\title{
Checkmate:
}

\section{A Chess Program for African-American Male Adolescents}

\author{
Mikhail Korenman \\ International Educational and Cultural Services \\ U. S. A. \\ Tamara Korenman \\ St. Xavier University \\ U. S. A. \\ Elena Lyutykh \\ Northern Illinois University, Dekalb \\ U. S. A.
}

This investigation looked at the influence of a chess program on adolescents' attitudes towards schooling at an alternative charter school in a high-risk urban context. Participants included school administrators, subject teachers, and 15 chess players, all of whom were African American male students from lowincome backgrounds. Interview data revealed that the game of chess had a positive impact on the adolescents' attitudes toward schooling in a number of ways by: (1) engaging these adolescents in interactions with a supportive school professional, (2) having the students socialize in a violence-free environment, and (3) providing students with opportunities to explore life beyond their neighborhood.

Playing Chess to Beat the Odds The School and the Chess Program Participants and Research Procedures Findings

Discussion and Implication References

Educators often fail to recognize the complexity of teaching students in socially marginalized neighborhoods because they simply perceive inner-city schools as places with many disadvantages caused by cultural poverty. When educators and researchers do not take into account the cultural experiences that students bring from their homes to their classrooms, the meaning of schooling becomes foreign to the students and to their parents. Ignorance of the values cherished by the community creates a conflict, which in turn results in students' disengagement from schooling and in high dropout rates (Murray \& Naranjo, 2008). Creating a school environment that supports engagement of inner-city students in learning demands that educators rethink the structure of school and consider alternative curriculum components (Brown, 2007; Garcia, Mcllroy, \& Barber, 2008). This article describes a chess program embedded in the curriculum of an alternative charter school in a high-risk urban context and 
identifies specific factors of the program that positively influenced students' attitudes toward schooling. Insight into the positive school experience of students from marginalized inner-city communities will assist educators in the development of school environments that promote positive school experiences.

\section{Playing Chess to Beat the Odds}

Contextual factors have long been recognized as important in understanding why students of color often fall behind in academic settings. Bourdieu and Passeron (1977) coined the term "cultural capital" to represent the accumulation of cultural knowledge, skills, and abilities possessed and inherited by the privileged groups in a society. Formal schooling plays an important role in transmitting cultural capital (education, language), social capital (social networks, connections), and economic capital (money and other material possessions) from one generation to the next. This process insures that the dominant groups within the society maintain power because they have access to the specific forms of cultural capital and are supportive of the status quo, thereby limiting the social mobility of the underprivileged groups.

Yosso (2005) extended the perspectives of Bourdieu and Passeron, arguing that educators should recognize the experiences of people of color in a critical historical context. Yosso went beyond a mere explanation of social and cultural reproduction by recognizing that even the most economically poor communities are, nonetheless, culturally wealthy. This cultural wealth includes an array of knowledge, skills, abilities, and contacts which the community possesses and utilizes for survival when trying to cope with various forms of oppression. Thus, the communal values, knowledge, and attitudes that students bring into the classroom need careful consideration if educators are going to develop equitable educational programs.

Educators often blame minority students and their families for poor academic performance despite evidence that a supportive school environment can make a difference in students' academic life. Croninger and Lee (2001) found that, although demographic, academic, and social risk factors were predictive of the school dropout rate among students, having a supportive relationship with a teacher (i.e., teacher closeness) and active teacher involvement (i.e., ongoing communication about students' school work) significantly increased students' motivation to stay in school. This effect was particularly strong among youth who had the highest risk of dropping out. Wayman (2002) summarized factors that moderate the effects of individual vulnerability and enable at-risk students to "beat the odds" and succeed despite settings that usually imply failure. According to Wayman, schools should strive to implement resilience-building strategies as curricular components and daily routines. These strategies require students to be more involved in school in ways that go beyond traditional classroom instruction. 
Thus, educators must look for ways to engage students in school, to build their confidence and to make their educational experiences more meaningful inside and outside of the classroom. The game of chess is one such activity that can help strengthen students' academic skills and nourish the development of positive behaviors. Hanners (1990) and Kinhart (2005) described the game of chess as a unique interaction of two players who compete intellectually and learn from each other. Chess educators have argued that chess instruction provides rich experiences for the development of academic skills. Studies reported that students who regularly attended sessions with a chess coach improved their academic test scores by $17.3 \%$ compared to only $4.6 \%$ improvement for students participating in other enrichment activities (Polgar, 2008). There is also evidence of the positive impact of chess playing on the development of pro-social behavior in students at risk of academic failure. When playing chess, young adolescents learned to respect the decisions of their opponents; this had a positive influence on the development of conflict resolution skills. Fried (1992) and Gaines, Berkovitz, and Kohn (2000) reported that after participating in a school-based chess program, adolescents who exhibited self-centered and aggressive behaviors showed an increased willingness to change their behavior for the better.

The transformation of troubled inner-city adolescents into career-oriented, ambitious young adults, which took place in the course of playing chess, attracted the attention of film producers. The Mighty Pawns (Laneuville, 1987) and The Knights of the South Bronx (Nabatoff \& Hughes, 2005) tell stories of students notorious for chronic truancy, vandalism, and thievery. In an effort to learn the traps and sacrifices involved in the game, these students found themselves reading chess books, traveling, and competing in national and international chess tournaments. Recently Cerini (2004) and Copeland (2004) conveyed similar stories of how the game of chess became a life-changing experience for students from the inner-city neighborhoods. In particular, Copeland's story celebrated a teacher who "shared his passion for chess with his students. He was teaching them to control the center and they learned to control themselves" (p. 1).

Adolescents from high-poverty inner-city environments are at higher risk of dropping out of school due to the marginalization of their cultural capital in the mainstream classroom. The failure of many schools to engage these adolescents in meaningful ways often results in academic failure. Prior research indicates that schools in high-risk environments must strive to provide opportunities for students to experience success, to build supportive relationships with adults, and to feel confident about their chances of finishing school. Playing chess has been found to have a positive impact on academic and social skill development in children and adolescents of various backgrounds. This study will extend existing research by examining specific ways in which a chess program played a positive role in the lives of 15 young African American men at an alternative school in an impoverished urban neighborhood. We will bring voices of the teachers, administrators, and the young men themselves to paint their own picture of the impact of chess playing. 


\section{The School and the Chess Program}

The alternative charter school where this study took place is located in an impoverished city neighborhood with a history of violent crime, high levels of gang activity, and drug-related crimes (Neighborhood Scout, 2008). Similar to other such neighborhoods, this impoverishment is primarily due to the decline in manufacturing jobs, middle-class flight, and White flight that took place in many communities in the 1950s (Wilson, 1987). These factors contributed to the widespread displacement of workers, chronic unemployment, and widespread poverty; the factors were made worse by the lack of investment in urban communities during the late 1970s and 1980s (Lipman, 2004; Wilson, 1987). Like many other alternative schools, this charter school was created in response to the demand for a school environment that is supportive of inner-city students. Many alternative schools in urban and metropolitan areas serve communities that McWhorter (2000) framed as "pathological ghetto culture" (as cited in Lynn (2006, p. 107).

The school in this study is a member of a charter school network composed of 23 campuses serving students who have dropped out of school. The school provides former dropouts with an opportunity to complete the coursework that they lack for graduation. Some students are enrolled in this school for only one or two semesters while others stay for several years. The network personnel, who identify school dropouts and offer them admission to the alternative education system, govern the admission process to this alternative charter school. The admission process requires the students to take the Test of Adult Basic Education (TABE) for placement purposes.

Soon after arriving at the alternative charter school as a newly hired science teacher, the lead investigator set up his chessboard to entertain students in the lunchroom. At first the students were perplexed. Most did not know the names of the chess pieces or how and why the pieces were moved. Some students stood around in a circle, watching the investigator play chess with another teacher and trying to learn the moves. Others did not show any interest in the game. After several weeks, the investigator offered individual sessions to those interested and explained the rules of the game. From that point on, the change in the students' interest in chess playing was rapid. This change was further intensified when a student won a game against the investigator for the first time. This individual victory became a source of collective pride for all of the students. After this first victory, students appeared more motivated to learn how to play chess. Many became competitors who took each game seriously. They refused to give up until they were checkmated. Each small victory became a step on the way to a big success.

The school principal recognized the students' interest and agreed to purchase 10 chess sets. The students used all 10 chessboards to play chess daily in the lunchroom. The following spring, the investigator took the school 
team to compete at the U.S. Chess Federation National High School Championship. None of the members of the team had participated in any chess tournaments prior to that event. Nonetheless, the tournament was a success; each team member won at least one game and the team finished $15^{\text {th }}$ among 32 teams in their category.

In response to the success at the national competition, the school principal approved a chess course as an elective and included the course in the school schedule for the following semester. Chess became the only elective course in the curriculum. Those students who needed to maintain a full day of school were automatically assigned to the elective chess class. Thus, 30 students enrolled in three sessions of the chess class and met every day for chess instruction. The class followed a chess curriculum developed by the first investigator, which included thematically sequenced in-class verbal instruction and chess problems. The students also received a booklet with chess winning strategies and exercises for an individual challenge. Grading criteria for the class included participation, effort, and completion of the individual challenges in the booklet, which required an application of the strategies covered during the class lectures.

The investigator made the routine easy to follow. On a typical day upon arrival to the class, the students took their seats and set up the chess pieces on the boards. The investigator would introduce the topic for the day and start his lecture, showing a game on a display board posted on the wall. Every day he discussed various strategies for the opening, attack, defense, and the ending of the game. Students listened and asked questions during the lecture. Sometimes the investigator would display a portion of a game and ask students to come up with a winning strategy. After the lecture, students played chess with each other. The investigator also played with students one on one and modeled a "think aloud" strategy explaining the moves while other students watched. Once a week, students had a chess competition among classmates. The instructor did not lecture on that day; students played during the whole class period. Following the class tournament, players would analyze their own game and request the instructor to discuss whether or not they made the right moves during the game.

\section{Participants and Research Procedures}

The data for this study came from interviews with the students, teachers, and school administrators. All participants were approached individually and asked if they would be willing to be part of the study and to evaluate the impact of the chess program on the students' attitude toward schooling. All who were approached agreed to participate. The study was conducted upon approval from the Institutional Review Board. To ensure confidentiality, researchers did not use the real names of the participants when collecting and analyzing the data.

The first group consisted of the school administrators; the principal and assistant principal represented this group. The school principal, an African 
American female educator with over 30 years of experience in the field of education, had founded the school 30 years ago. The assistant principal was a former science and math teacher who was very familiar with the school environment and experienced in managing the students and supporting their learning. The second group of participants included academic subject teachers. Eight faculty members represented this group: five males and three females. Only two faculty members had taught in this school for more than 10 years and were considered veterans. The remaining teachers were relatively new. Typically, $30 \%$ of the faculty was replaced every summer. The third group of participants consisted of 15 students who had played chess consistently during four semesters and represented the school's chess team. All of the student participants were African American males from low-income backgrounds. The age of participants ranged between 17 and 21 years, with the majority of students being 18-20 years old. Six participants were homeless; six participants lived with a single mother; and the rest of the participants had families consisting of a mother and a stepfather. Four of the students were assigned to the special education program and had Individual Educational Plans. All of these students were school dropouts who had returned to the alternative charter school to complete high school.

The lead investigator conducted 30-45 minute semi-structured interviews. All interviews were recorded. During the interviews with the school administrators and the teachers, the researchers asked open-ended questions about (1) the reasons that made the school administrators decide to implement and sponsor a chess program at their school, and (2) the changes in the school environment and in students' attitudes that the administrators and the teachers observed as a result of implementation of the chess program. During the interviews with the student participants, the researchers wanted to find out: (1) why students liked to play chess, (2) how participation in the program influenced the students' attitude toward schooling, (3) whether learning chess helped them learn other subjects, and (4) whether participation in the chess activities impacted the social life of the chess players.

The second researcher transcribed the interviews. A coding scheme was developed and discussed by the second and the third researchers who followed the multistage process described by Miles and Huberman (1994). First, researchers listed the answers of each group of participants that were given when the participants answered the interview questions. Then, researchers made rough categories of answers that thematically belonged together and coded them with the key words. The key words formed the skeleton of the coding scheme which was subsequently applied to all transcripts. To ensure inter-rater reliability, three researchers picked one interview each and coded that interview independently. The researchers then compared their individually coded transcripts and made note of any discrepancies. The discrepancies were discussed and the coding scheme was amended. Researchers used this scheme to code all 25 interviews. To ensure that there were no significant omissions and discrepancies in the coding, the lead researcher listened to all of the interviews in their entirety while reading the transcribed and coded interviews. The last step in 
the data analysis involved listing the answers of the participants per code and the subsequent grouping of the codes into thematic categories.

\section{Findings}

The researchers identified four thematic categories-challenge, culture, motivation, and support-which provided the framework for understanding how the chess program improved students' attitudes towards schooling.

\section{Challenge: A Desire to Compete and to Win}

One major theme that emerged from the responses of the student participants was that they desired a challenge and a chance to win. The players explained that chess appealed to them because the game challenged their minds. The students appreciated the opportunity to fight intellectually: "Chess keeps my brain working. I like to battle." Another interesting comment indicated that the young men viewed chess as a masculine activity and thus worthwhile pursuing: "Chess is a game of men." Other responses revealed the students' appreciation for the opportunity to make their own decisions: "I like the excitement of choosing my strategy to win." Competition was another theme common to all student responses:

...I want to learn more about the game and hope to come back from the next National tournament undefeated. I have always been competitive in sports, especially basketball which I have played in leagues in and around Chicago, and now I feel the same way about chess. But chess is different. Chess makes you think hard, real hard, if you want to win. I got better because I was so sick of losing. I think the best thing someone can do to get better is to compete against players that are better than him or her. I just got sick of losing and started to watch what other players were doing - trying to pick up on their defense moves.

The students also believed that chess helped them become recognized by their peers and school community members. Participants discussed that being recognized at their school made them feel important. "The school paid for us to go play out of town. It meant they believed in us so we better play well." Other participants recalled, "On the way back from the tournament, all the people at the airport wanted to know what we got our medals for. I got tired explaining; but God, it felt good!" Both administrators also confirmed the elevated spirit at the school when the chess team had returned from the National tournaments. The team competed three times at the National level, and every time players brought trophies and medals to their school. Both administrators believed in the importance of the chess program and expressed their intent to support and to expand the program in the future. 


\section{Leaving the "Culture of Poverty" Behind}

The administrators and the students agreed that the opportunities to travel and to participate in the chess tournaments were unique experiences for all of the students. Many of the participants had never left their neighborhoods before going to these chess tournaments. Traveling out of town by airplane, staying in first-class hotels, and dining in fine restaurants were remarkable experiences. A participant commented, "If it was not for chess, I would never have been able to see the Chiefs stadium in Kansas City. Now I show my pictures from Kansas City and Atlanta, and all my friends get jealous. They think I am a hero." Thus, the students became involved in the exploration of life beyond their neighborhoods; this opened their horizons and showed them important educational goals in life that they can strive to attain.

One of the young men described his excitement at the tournaments:

I was nervous when we first arrived at the event and looked over the room. There was table after table after table with chess sets laid out. There were like 2000 players in the hall; and when the playing began, it was so quiet you could hear a pin drop.

The Spanish teacher who accompanied the players in their travel to compete in the tournaments believed that this excitement influenced the players' sense of responsibility. "Players became better organized, punctual, and focused. They were supportive of each other when they faced success and failures during tournaments as they exhibited behaviors of responsible and mature young people."

When players traveled for participation in the national and regional tournaments, the behavior of players changed as soon as the team arrived at tournaments. They walked and acted differently. On the trip, these mature, responsible, and focused young adults followed the rules when they stayed in the hotels and dined in the restaurants. Moreover, during the tournament, none of the players were late or unprepared for their matches. All team players were neatly dressed and well mannered in their interactions with each other and with other players.

During their spare moments, the students continued to play chess while sitting on the floor at the hotel and at the airport; they used this time to analyze best strategies to win a game. They used the time between matches for analysis of their games speculating on better ways to finish a game. It seemed as though they adopted a different behavior pattern and displayed different qualities when they were away from their routines. The school principal commented that chess provided students with an opportunity to battle for success. She believed that when the students learned a strategic game, they realized that in order to be successful they had to think of an approach, make a decision, implement a strategy, and take responsibility for their actions. Sometimes they would win and 
other times they would lose. Losing meant the students needed to learn from their mistakes and to practice more to be able to win the next game.

\section{Motivated to Learn}

When student participants discussed how the chess program influenced their attitudes toward schooling, they indicated that they had developed an interest in going to school. A student commented, "Here you try hard to make it to the team. You try for many days and weeks and then, when you finally made it, it feels good." The effort of the chess players was rewarded. They appreciated the time spent with their chess coach who engaged them in a "fun" activity and helped them discover that their learning could be rewarded.

The subject teachers talked mostly about their observations of the change in some students' academic behaviors. Among other things, several teachers noted a positive change in the chess players' motivation toward schooling. The teachers commented that those students who had taken chess for a longer period of time (i.e., more than one semester) seemed to display increased interest towards learning in academic subjects. Both math and science teachers observed improvement in the chess players' attention span. The English teacher noticed, "Students, who now spend hours sitting at the chessboard and study chess in silence, often could not previously sit still for 15 minutes in the classroom." In addition, the subject teachers also noticed that the students had developed patience and persistence in the face of a difficult task. The math teacher commented, "...these people learned not to give up. If something does not go their way, they don't just get angry and quit. Instead, they take their time to think about the problem and then to come back with a new idea."

The student participants also discussed how learning chess helped in learning other subjects. This theme in the participant responses indicated that when students studied chess, they read a book with a purpose and this skill increased their ability to complete assignments in other classes. They also indicated that they felt more comfortable staying focused until the task was completed. The following represents some participant comments:

These chess books have lots of tips on how to be good at it. Now I feel like I trust other books too.

I see nothing wrong with just reading it and answering questions on my worksheet. I used to hate worksheets.

I guess I am more patient now. I just sit and listen to what this assignment is all about and what I need to do to get this done. 


\section{Support: Sharing a Passion}

School administrators also talked about the nature of the alternative school. The school opens its doors daily to 170 students who once lost the opportunity to graduate from high school for various reasons. Many students at school had such high-risk experiences in their backgrounds that "the alternative school was for students who had no alternatives." It is always a challenge in this environment to find teachers who are truly committed to helping these young people succeed. The principal felt, therefore, that it was important to encourage teachers to teach to their passions, be it chess, math, or art, so that the students can have adult role models who care deeply about the subject and who believe in students' success.

The chess players spent an hour a day with the chess coach. The assistant principal believed that this positive interaction of former school dropouts with an adult who wanted to help them win the game had a meaningful influence on students. The assistant principal explained that students ended up at this school partly because most of them had never had positive interactions with adults. According to the assistant principal, when teachers cared to share their hobbies with the students, they opened doors to trust in relationships and created moments for laughs and sincere conversations. Such interactions showed the students a different, more authentic meaning of leaning that rarely happens in a traditional school setting.

Student participants agreed with the statement, "It was nice to have someone at school who really wants you to win. The coach is tough and he expects you to get just as tough to go through the steps to win a game." Other participants indicated, "When you play chess at school, time flies fast." Many of them mentioned, "I wish we had all classes like this."

\section{Discussion and Implication}

Our findings suggest that students involved in the chess program (1) played a competitive game that built on their existing skills, (2) had an opportunity to explore life beyond the neighborhood, (3) improved their academic motivation, and (4) experienced support by a caring professional. Together these characteristics of the chess program helped improve the students' attitudes toward schooling.

Previous research on the education of African American males suggests that being competitive, challenged, and excited are important components for a successful school experience because these components reflect the values of the African American community (Stovall, 2005). Also, a relationship of care and trust becomes an important factor in the development of a positive attitude of students toward schooling (Nieto, 1999; Perez, 2000; Valenzuela, 1999). 
This study agrees with previous reports that chess programs are successful due to the competitive, challenging, and thereby exciting nature of the chess game. Additional positive influence came from the attention and support of an adult who worked with the students to ensure their success. The coach guided students in their learning to be responsible adults as they represented their school at the tournament and explored life beyond their neighborhood. This exploration turned academic tasks (i.e., reading the books and investing an effort in learning) into an authentic necessity for winning in the game (Ashley, 2008).

Finally, as noted by Bourdieu and Passeron (1977), marginalized communities lack social mobility due to limited access to social and cultural capital and, therefore, have a tendency to reproduce themselves. This current study shows that involvement in the chess program offered students a chance to explore life beyond their immediate surroundings and to learn about numerous opportunities that exist in a democratic society. Practitioners who teach in highrisk marginalized communities must put an emphasis on creating additional opportunities for their students, setting goals, and experiencing success inside and outside of the classroom.

There are several implications of this study for practitioners. First, it is important to consider expanding the involvement of high school students in chess. As reported by the United States Chess Federation, in recent years the majority of scholastic chess players have been elementary school students (Scholastic Chess, 2008). In middle school and then high school, students became involved in athletics and other extracurricular activities. Our findings, however, suggest that chess can also improve the attitudes towards school of adolescents from impoverished neighborhoods.

Second, school educators should consider a wider incorporation of chess instruction in the high school curriculum in urban high-risk contexts. When chess is offered as a curriculum component and is included in the school schedule, it does not require students and administrators to stay after school or necessitate additional transportation to make the program accessible for all students. Also, incorporation does not require expensive facilities and equipment and thus can be a low-cost option that provides rich experiences that might otherwise be unavailable to the adolescents.

Third, practitioners should be aware of the importance of chess instruction as a component of a chess program. The chess clubs that exist in some schools usually have the students play chess with each other. Supervisors often limit their duties to chaperoning the students who come to a chess club. When instruction is not provided, the students do not receive systematic guidance in problem solving and strategic thinking. In addition, the valuable coach-student interaction is missing. Thus, having actual instruction in chess is a factor that helps maximize the positive influence of chess playing on students' attitudes.

A chess program integrated into a high school curriculum had a positive impact on adolescents' attitudes towards schooling in a high-risk urban context. Feedback from school administrators, teachers, and chess playing students in an 
alternative school revealed that the game of chess engaged these adolescent students and expanded their life opportunities. The students showed a desire to succeed and put considerable effort into learning winning strategies. When students experienced a feeling of success, their self-efficacy increased. As one of the chess players remarked, "I am thinking now of going to a college, studying in a library and, who knows, some day, I may be running for president."

\section{References}

Ashley, M. (2008). Motivating urban youth to achieve educational excellence. Cleveland, $\mathrm{OH}$ : City Club of Cleveland.

Bourdieu, P., \& Passeron, J. (1977). Reproduction in education, society and culture. London: Sage.

Brown, T. (2007). Lost and turned out. Urban Education, 42(5), 432-455.

Cerini, K. (2004, August 6) The Great Knights exposes children to educational opportunities through playing chess. Long Island Business News. Retrieved October 22, 2008, from http://ezp.sxu.edu/login?url=http://search.ebscohost.com/login.aspx?direct $=$ true \&db=bwh\&AN=L5469766LIBN\&site=ehost-live\&scope=site

Copeland, L. (2004, June 16). Black youths learn to make the right moves; Chess teacher Orrin Hudson uses the ancient game to try to rescue troubled teens. USA Today. Retrieved October 22, 2008, from http://www.usatoday.com

Croninger, R., \& Lee, V. (2001). Social capital and dropping out of high school: Benefits to at-risk students of teachers' support and guidance. Teachers College Record, 103(4), 548-581.

Fried, S. (1992). Chess: A psychoanalytic tool in the treatment of children. International Journal of Play Therapy, 1(1), 43-50.

Gaines, L., Berkovitz, I., \& Kohn, B. (2000). Chess as a way of improving object relationships in narcissistic teenagers. In A. H. Esman, L. T. Flaherty, \& H. A. Horowitz (Eds.), Adolescent psychiatry: Developmental and clinical studies (pp. 187-199). Mahwah, NJ: Analytic Press.

Garcia, D. R., Mcllroy, L., \& Barber, R. T. (2008). Starting behind: A comparative analysis of the academic standing of students entering charter schools. Social Science Quarterly, 89(1), 199-216.

Hanners, C. (1990). Frankie, Stoney and the last chance boys. Seattle, WA: 
Turman Publishing Company.

Kinhart, L. (2005, May). Chessmate! National Education Association (NEA) Today, 23(8), 27.

Laneuville, E. (Director). (1987). The Mighty Pawns [Motion Picture]. United States: Bonneville Worldwide Entertainment.

Lipman, P. (2004). High stakes education: Inequality, globalization, and urban school reform. New York: Routledge Falmer.

Lynn, M. (2006). Race, culture, and education of African Americans. Educational Theory, 56(1), 107-121.

McWhorter, J. (2000). Losing the race: Self-sabotage in Black America. New York: Free Press.

Miles, M., \& Huberman, M. (1994). Qualitative data analysis $\left(2^{\text {nd }}\right.$ ed.). Thousand Oaks, CA: Sage.

Murray, C., \& Naranjo, J. (2008). Poor, Black, learning disabled, and graduating: An investigation of practices and processes associated with school completion among high risk urban youth. Remedial and Special Education, 29(3), 145-160.

Nabatoff, D. (Producer), \& Hughes, A. (Director). (2005). The Knights of the South Bronx [Motion picture]. United States: Allumination.

Neighborhood Scout. (2008). Retrieved October 22, 2008, from http://www.neighborhoodscout.com/il/chicago/independence-douglas/

Nieto, S. (1999). The light in the eyes: Creating multicultural learning communities. New York: Teachers College Press.

Polgar, S. (2008, April 27). Chess great Polgar committed to area children. Lubbock Avalanche-Journal. Retrieved July 17, 2008, from http://www.lubbockonline.com/stories/042708/col 272733825.shtml

Perez, S. A. (2000). An ethic of caring in teaching culturally diverse students. Education, 121(1), 102-105.

Stovall, D. (2005). A challenge to traditional theory: Critical race theory, AfricanAmerican community organizers, and education. Studies in the Cultural Politics of Education, 26(1) 95-108.

Scholastic Chess. (2008). The United States Chess Federation. Retrieved October 22, 2008, from 
http://main.uschess.org/content/blogsection/27/131/

Valenzuela, A. (1999). Subtractive schooling: U.S.-Mexican youth and the politics of caring. New York: SUNY Press.

Wayman, J. C. (2002). The utility of educational resilience for studying degree attainment in school dropouts. The Journal of Educational Research, 95(3), 167-179.

Wilson, W. J. (1987). The truly disadvantaged: The inner city, the underclass, and public policy. University of Chicago Press.

Yosso, T. J. (2005). Whose culture has capital? A critical race theory discussion of community cultural wealth. Race, Ethnicity, and Education, 8(1) 69-91. 